\title{
Editorial
}

\section{EPJ: AP at the turn of the century, the right moment for a new take-off?}

The European Physical Journal: Applied Physics is now turning into its fourth year of existence. It has survived in spite of a hard childhood. Michel Sauzade, our co-editor in chief, passed away suddenly at the end of the first year. As he had been very positive into our common task of launching this new Journal, resulting from the merging of Journal de Physique III with Microscopy, Microanalysis, Microstructures, the situation became quite critical. Furthermore this sad event was superposed to all the problems which a new title has to face within the present context of strong competition between journals and with the electronic press. We could continue, mostly thanks to the efforts of all members of the Editorial Board, and in particular of the most ancient ones, whom I want to warmly thank for their permanent support all along these past years.

It seems now reasonable to strike a first balance after three years of publication. All indicators, relative to the numbers of manuscript submissions, to the rate of acceptance, to the widening of the geographic origin, to the distribution between the major topics, suggest that we are heading into the right direction. However, the changes have not yet been sufficiently established. We definitely need more manuscripts of high quality from all around the world, and in particular from European countries, in order to improve the fit of the content of the journal with its title. The situation is now ready for building a more stable organisation of the Editorial Board. Two Editors-in-Chief have therefore been appointed, one of them covering the Materials Science topics and the second one being in charge of the other subjects with a strong emphasis on the Optics, Photonics and Electronics sections. The Editorial Committee is being renewed by half, in order to adapt more consistently the extent of the competence which they represent to a field of research and development in rapid evolution. This will also show through the changes introduced into the definition of the headings in the Aims and Scopes, which you will find in the appropriate pages of this issue.

Among the publishing policies which we want to stimulate in future issues, let us first quote the topical issues. Our intent is to gather in two or three issues every year, a collection of papers dealing with subjects of high present interest. The selection of these "hot topics" will greatly depend on the actuality and on your own suggestions. Another evolution concerns the Rapid Notes. Although they have existed since the start of the journal and they correspond to a regular demand of our community (fast publication of short papers, less than four pages, describing important advances), the EPJ: AP Rapid Notes have not been as popular as expected. We wish to make them more attractive, with an increased rapidity of publication and a different lay-out to separate and distinguish them from the other papers in the same issue. You are therefore fully encouraged to use these possibilities.

We hope that these small advances will make the journal more popular. However, what makes a journal alive are really the authors. Therefore we expect that you will submit contributions of highest quality which will find a large audience in EPJ: AP, a member of the wide family of European Physical Journals. Let us wish all together a long and rich life to the Journal and a Happy New Year to all of you !!! 